\title{
LA PLAZUELA DE LOS DESAMPARADOS Y SU ENTORNO URBANO-MONUMENTAL: VALORACIÓN HISTÓRICA DE LA CONSTRUCCIÓN DE UN LUGAR ${ }^{[*]}$
}

\author{
THE PLAZUELA DE LOS DESAMPARADOS AND ITS URBAN-MONUMENTAL ENVIRONMENT: \\ HISTORICAL VALUE OF THE CONSTRUCTION OF A PLACE
}

JONATHAN RAVINES CASAS ${ }^{[\star x]}$

Fecha de recepción: 30 de agosto de 2016

Fecha de aprobación: 26 de noviembre de 2016

\begin{abstract}
RESUMEN
Hace poco más de 70 años, en lo que hoy se conoce como el traspatio de Palacio de Gobierno, existió una plazuela cuya importancia e historia datan de las primeras décadas de la fundación española: la Plazuela de los Desamparados. Este espacio público fue famoso por la intensa dinámica urbana que en él tenía lugar. La plazuela era el primer espacio de recibo de los limeños que venían del barrio de "abajo del puente", así como lugar de congregación de la orden jesuita, quienes solían impartir clases en la escuela ubicada al lado de la Iglesia de los Desamparados. Configuraban la plazuela la Iglesia de Nuestra Señora de los Desamparados y al Arco del Puente de Piedra, elementos de gran valor arquitectónico y patrimonial que sucumbieron junto con la plazuela por los avatares del destino y de la modernidad. Este artículo pretende hacer una pequeña remembranza sobre la desaparecida plazuela, y una reflexión sobre el estado actual de este espacio y su posible recuperación para la ciudad.
\end{abstract}

\section{PALABRAS CLAVE}

Plazuela, patrimonio, renovación urbana

\begin{abstract}
Just over seventy years ago, in what is now known as the patio of the Government Palace, a plazuela (small plaza) existed: the Plazuela of the Helpless. Its importance and history date back to the early decades of the Spanish foundation of the city. This plazuela was the space that first received Limeños from the neighborhood of "those below the bridge", as well as a place of congregation for the Jesuit order, who also used to teach at the school located next to the Church of the Helpless. The Church of Our Lady of the Helpless and the Arch of the Stone Bridge comprise the plazuela. These elements, of great architectural and heritage value, succumbed alongside the small plaza due to the vicissitudes of fate and modernity. This article intends to be a small remembrance of the missing plazuela and to reflect about the actual state of this space and its possible recovery for the benefit of the city.
\end{abstract}

\section{KEYWORDS}

Plazuela, heritage, urban renewal

$\left(^{*}\right)$ El presente artículo es una síntesis del trabajo de investigación realizado en la asignatura de pregrado de Taller de Investigación en Historia (THIS) de la Facultad de Arquitectura, Urbanismo y Artes de la Universidad Nacional de Ingeniería. El trabajo de investigación que da origen al artículo se inició en el curso de Arquitectura Peruana 3, dictado por el Arq. José Beingolea Del Carpio; se desarrolló en 2015 en la asignatura de THIS 1, bajo la responsabilidad del mismo docente; y se concluyó en el THIS 2, a inicios de 2016, siendo docentes del curso el MSc. Arq. Carlos Guzmán García y MSc. Arq. José Hayakawa Casas.

(**) Estudiante de Arquitectura de pregrado del décimo ciclo de la Facultad de Arquitectura Urbanismo y Artes de la Universidad Nacional de Ingeniería (FAUA-UNI). Representante del Tercio Estudiantil de la UNI ante el Consejo Universitario. Partícipe del workshop Barrios Altos Resiliente. Actualmente labora en la asociación Habitar Construcción Colectiva, colectivo que llevar a cabo proyectos en zonas de riego para mejorar las condiciones de vida de la población residente mediante el establecimiento de alianzas entre la comunidad y los profesionales. Contacto: ravinesfaua@gmail.com 
Figura 1. Plano de ubicación donde estaba situada la Plazuela de los Desamparados

Fuente: Google Earth, 2016.

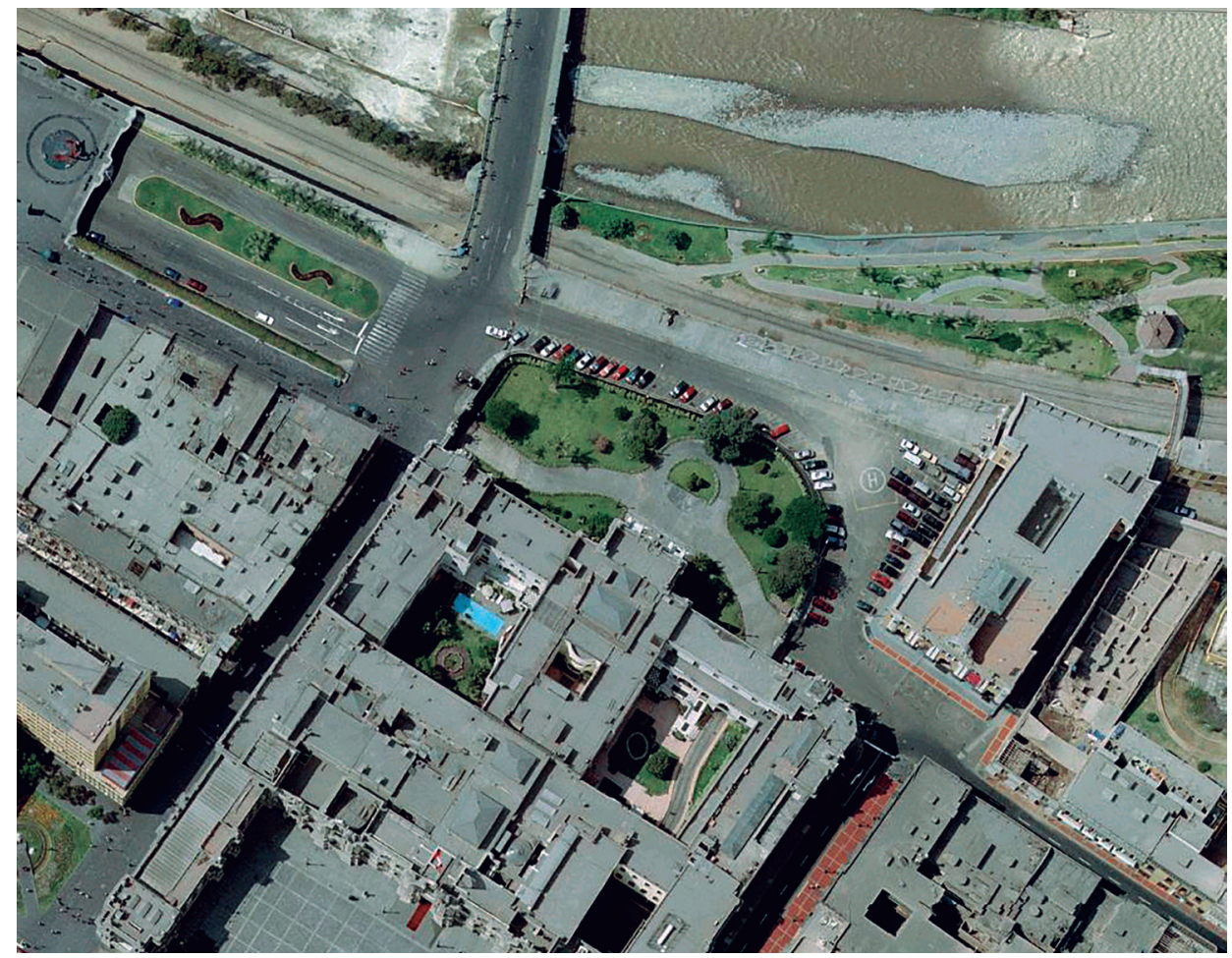

En la actualidad, la primera cuadra del Jr. Áncash es un espacio configurado por el tras patio de Palacio de Gobierno, la Fachada lateral de la Estación de los Desamparados, hoy Casa de la Literatura, y la ribera del río Rímac, acogió décadas atrás a una importante iglesia virreinal: la Iglesia de Nuestra Señora de los Desamparados, la plazuela del mismo nombre y al Arco del Puente de Piedra. Este antiguo espacio público, muy rico en su dinámica urbana, a decir de Jorge Basadre "...el rincón quizá más lleno de ambiente en la ciudad" $(1945,382)$, supo sobrevivir a los cambiantes acontecimientos de nuestra historia urbana durante muchos siglos, pero sucumbió al aplastante paso de la modernidad en aras de un 'progreso' manifestado en la renovación urbana y arquitectónica llevada a cabo durante las primeras décadas del siglo XX. Estos cambios no solo se concretizaron en la pérdida del patrimonio material de este espacio público, sino también en la paulatina pérdida de los valores simbólicos de identidad y de uso (Figura 1).

¿Se puede recuperar este espacio público para la ciudad?

¿Qué beneficios conllevaría la renovación integral de este espacio público para el tejido urbano del Centro Histórico y para los habitantes de la ciudad?

\section{Plazuela de los Desamparados, contexto patrimonial urbano}

El espacio que comprendió la Plazuela de los Desamparados está ubicado dentro del antiguo casco del Centro Histórico de Lima, donde se encuentran edificios de carácter patrimonial como el Palacio de Gobierno, la casa Aliaga, la antigua Estación de los Desamparados y el Puente de Piedra. Además, también forma parte de su contexto inmediato la ribera del río Rímac. Este espacio en su conjunto es uno de los ambientes urbanos cuya composición primigenia ha sufrido muchas alteraciones, como consecuencia de sucesos como la partición de la manzana del "Carmen" (donde se ubica la casa Aliaga), la desaparición de la manzana entre la calle Polvos Azules y la ribera del Río Rímac, las 
reedificaciones del Palacio de Gobierno y la estación de los Desamparados, y la destrucción de la propia Plazuela de los Desamparados. La estratégica ubicación de este espacio permite abrir el debate sobre su actual situación y la validez de su recuperación.

\section{Plazuela de los Desamparados, contexto histórico-urbano}

La primera aproximación hacia la Plazuela de los Desamparados se centrará en el tejido urbano del cual fue parte a lo largo de la historia de nuestra ciudad, desde la fundación hasta mediados del siglo XX.

\section{La Lima fundacional}

Cuando los españoles llegaron al valle del Rímac ya se estaba implantando en las nuevas urbes que se fundaban a lo largo de América una forma de trazado urbano similar a los clastrum romanos. Francisco Pizarro, que había tenido participación en la creación de varias ciudades en La Española (primer asentamiento español en República Dominicana), aplicó los conocimientos adquiridos y fundó la ciudad de Lima el 18 de enero de 1535, siguiendo una traza en forma de damero. Lohmann afirma al respecto que "A partir de la plaza, centro irradiador de la actividad urbana, se delineó sencillamente una cuadrícula, reminiscencia de los campamentos romanos y fácil de aplicar cuando no se tropieza con edificaciones preexistentes u obstáculos naturales que condicionaran el trazado" (Gunther \& Lohmann, 1992, p. 63).

La forma de la recién fundada ciudad tuvo una función geopolítica, pues era utilizada como un elemento de control de la población: "La cuadrícula estuvo presente permanentemente en la construcción urbana del poder virreinal, constituyendo un referente, un signo, un símbolo que propició la difusión y la reproducción del orden colonial" (Saénz, 2015, p. 4)

\section{El damero de Pizarro y la Lima amurallada}

Décadas después del establecimiento del virreinato del Perú, ante el creciente desarrollo de la ciudad, y el latente peligro que significaba para las autoridades y los habitantes de la ciudad el asedio de piratas en las ciudades hispanas, surge la propuesta de amurallar la ciudad. Este proyecto de gran escala suponía construir muros, bastiones, e ingresos alrededor del nicho urbano y parte de las áreas cultivables, excepto el barrio de San Lázaro y el Cercado de los Indios. Este último sector no fue considerado debido a que incrementaría el costo de la obra en gran medida, y a que se encontraban en las inmediaciones estribaciones como los cerros El Agustino y San Cosme, que podrían ser tomados cuando el enemigo quisiera atacar la ciudad. La concepción de esta obra fue concebida por el padre jesuita Jean Corninck en el año 1673.

Las murallas que se construyeron alrededor de la ciudad no llegaron a cumplir el fin netamente militar previsto, pues la ciudad de Lima nunca sufrió asedio alguno por parte de piratas y corsarios. Más esta estructura si tuvo otras funciones, que Sáenz menciona:

Se sabe que, en realidad, no hubo ningún ataque pirata en las costas de la ciudad de Lima. Por ende, la muralla no tuvo ninguna oportunidad para ejercer la protección de para la que había sido concebida... En términos de territorio, la Muralla limeña constituyó un elemento de organización y articulación del espacio rural y la ciudad. [...] La confinación de la ciudad aisló el espacio territorial de Lima, ahora la lectura de la ciudad era entendida en intramuros (núcleo urbano) y extramuros (áreas fueras de la muralla). (2004, p. 11)

\section{Los Borbones y la reforma del espacio público}

Tras la instauración de la Casa de los Borbones en España (1700), se sucedieron una serie de reformas en el ámbito político, económico, administrativo y urbano. Dentro de este contexto, la función de los espacios públicos fue parte de una sustancial modifica- 
devenir Vol. 3, N6, JULIO-DICIEMBRE 2016, PP. 79-97 - EstudIOS I ISSN 2312-7570

UNIVERSIDAD NACIONAL DE INGENIERÍ, LIMA

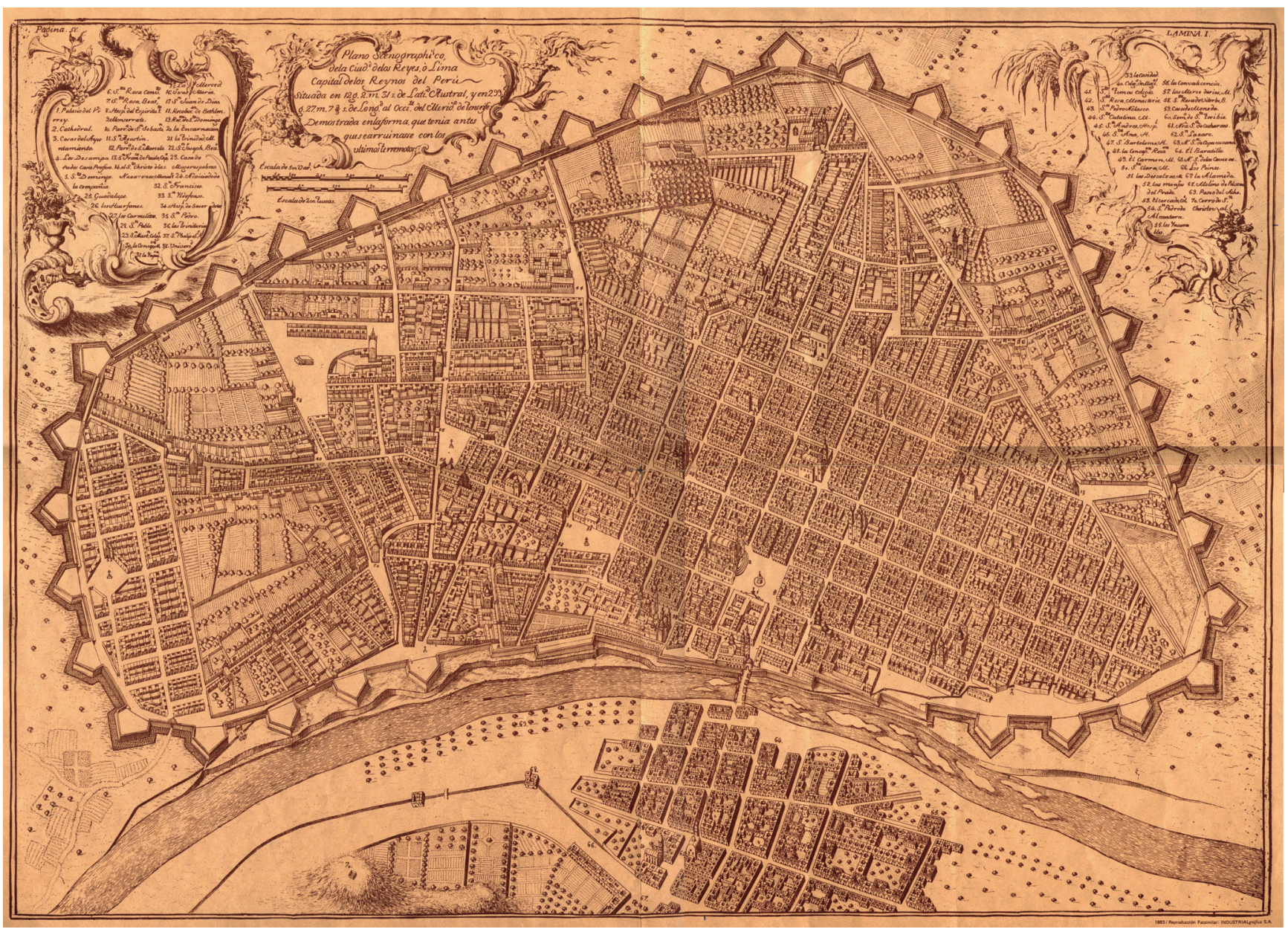

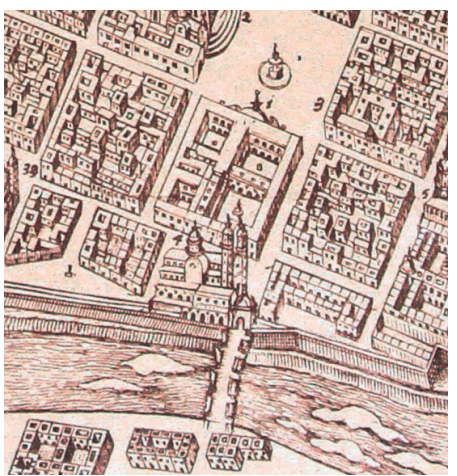

Figura 2. Plano de Lima de Pedro Nolasco, 1685

Fuente: Gunther, 1983.

Figura 3. Detalle de ubicación de la Plazuela de los Desamparados en el Plano de Lima de Pedro Nolasco, 1685 Fuente: Gunther, 1983. ción: el más notorio de estos cambios involucró a la Plaza Mayor, que a partir de entonces empezó a conocerse con Plaza de Armas. La reforma consistió en dotar a la plaza de carácter militar. Esta función que se sumó a las que cumplía la plaza previamente fue preponderante durante esa época. Los desfiles de las tropas reales, que tenían como fin demostrar el poder de la monarquía borbónica, se convirtieron en eventos que eran tomados como sucesos cotidianos por los limeños. Tras el terremoto de 1746 que azotó Lima, la política por parte de las autoridades virreinales incluyó la implementación de nuevos espacios para la recreación, el descanso y la contemplación, algunas de las funciones que la Plaza Mayor ya tenía. La construcción de la Plaza de Toros de Acho y el Paseo de Aguas son ejemplos tangibles de dicha política (Figuras 2 y 3 ).

\section{El antiguo Centro de Lima a inicios del siglo XX}

Tras la demolición de las murallas a mediados del siglo XIX, el crecimiento de la ciudad de Lima fue progresivo. Se caracterizó por el estilo afrancesado que tomó de manos de Enrique Meiggs, quien transformó los antiguos muros de la ciudad en bulevares y plazas. En los primeros años del siglo XX, durante el gobierno de Leguía, la expansión de la ciudad continuó a través de importantes ejes, como las avenidas El Progreso (actualmente Venezuela) y la Av. Leguía (actualmente Arequipa). Estos ejes permitieron conectar el centro de la ciudad con sus balnearios y el Callao, y a su vez le otorgaron un carácter metropolitano. La expansión urbana de Lima hacia el sur propició el desplazamiento de 
las familias de la oligarquía limeña hacia las nuevas urbanizaciones que se empezaban a formar. Este fenómeno trajo como consecuencia que la aristocracia limeña abandonara sus lugares de residencia en el centro histórico, que empezaba a ser ocupado por los migrantes que masivamente llegaban a la ciudad (Figura 4).

\section{De la Plazuela de los Desamparados al Malecón de los Desamparados}

En esta parte del artículo se describirá las etapas de desarrollo de la Plazuela de los Desamparados desde la época fundacional de la ciudad de Lima hasta mediados del siglo XX.

La intensa actividad que se desarrollaba en la ciudad durante las primeras décadas después de la fundación de Lima se evidenció también en el espacio comprendido entre la casa de Pizarro y la ribera del río Rímac, que daba al damero limeño. Es así que en los bordes de esta área se empezó a gestar una incipiente dinámica urbana debida principalmente a la aparición del molino de Aliaga y la instauración de la primera Casa de la Moneda. A su vez el comercio de esclavos traídos del 'Viejo Mundo' motivó que el espacio trasero de la casa de Pizarro sea empleado como lugar de refugio para estos. Asimismo, esta dinámica urbana se vio acrecentada en el año 1562, cuando el virrey Conde de Nieva propuso trasladar la picota, tronco de ajusticiamiento ubicado en la Plaza Mayor, al espacio posterior de la casa de Pizarro, como se consigna en el acta del cabildo fechada el 23 de octubre de 1562:

Prouision para que el rrollo y picora se quite de la placa y pase a la puente.

en este cabildo presento el señor corregidor una mandamiento e provision del salir viso Rey por el qual le manda el Rollo de la placa e como sea de gastar e donde se a de poner su temor del qual es de este que se sigue-pidió se asentase eneste libro---

don diego lopez de cunica y de Velasco conde denieva visoRey gobernador y capitán general enestos Reynos e prouincias del peru por su majestad-

Por quanto auiendo parescido cosa conveniente a la pulicia y ornato desta ciudad de los Reyer e por otros dines y Respetos que para ello a auido e cordado quel Rollo della se deshaga y quite y pase de la placa publica desta dicha ciudad donde al presente esta y se pase junto al Rio y el puente del.... (LCL)

Así, este espacio se convertió en el lugar donde se realizaban los ajusticiamientos públicos de la ciudad, a los cuales los pobladores acudían para presenciar los castigos. Muchos criminales ajusticiados eran atados al rollo, castigados y expuestos ante el público.

Debe indicarse también que donde inicialmente estuvo ubicado el Puente de Criznejas se construyó en 1610 el Puente de Piedra y el Arco Triunfal de ingreso a la ciudad de Lima. La construcción del puente, el único de piedra de la ciudad, significó un hecho importante debido a que permitía mantener la conexión entre la Lima cuadrada y el barrio de San Lázaro, y por ende con el camino hacia Trujillo.

En el año de 1629 el comerciante Bartolomé Calafre solicitó al cabildo este espacio para construir una capilla en honor a la virgen de Nuestra Señora de los Desamparados, de la cual era fiel devoto. El cabildo tuvo a bien aceptar la petición, como consta en el acta fechada el 13 de agosto de 1629:

Sobre el sitio de la capilla que se a de hacer nuestra señora de los desamparados (sic, por desamparados)---

En este cabildo se bio lo pedido por bartolome calafee morador en nuestra ciudad natural de la valensia el rracon del sitio de que pretende se le haga señalamiento y permisión en la placeta questa a las espaldas de las cassas rreales de palasio antes de la entrada de la puente del rrio donde antiguamente solia estar el rrollo y la capilla de los ahorcados para la fundación
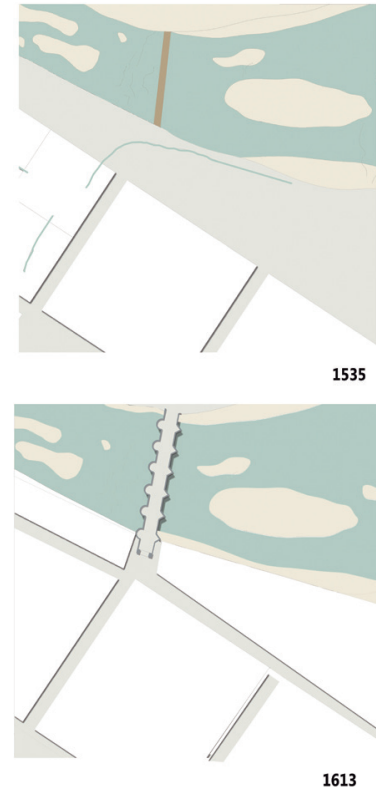

1613

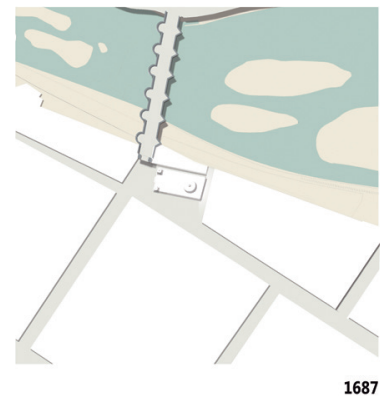

1687

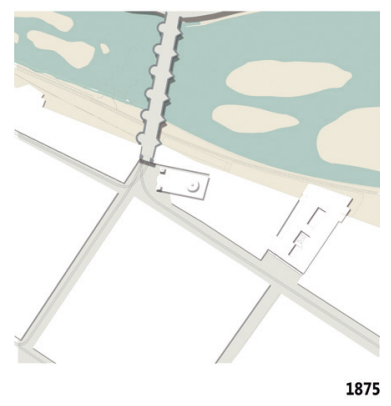

1875

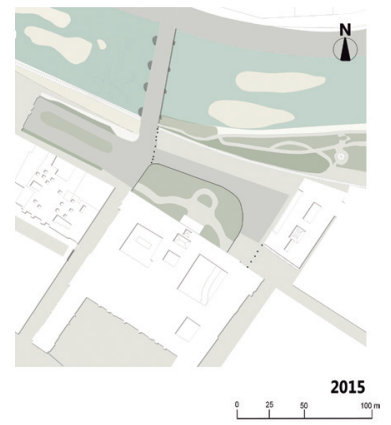

Figura 4. Evolución de la morfología de la Plazuela de los Desamparados Fuente: Elaboración propia, 2016 

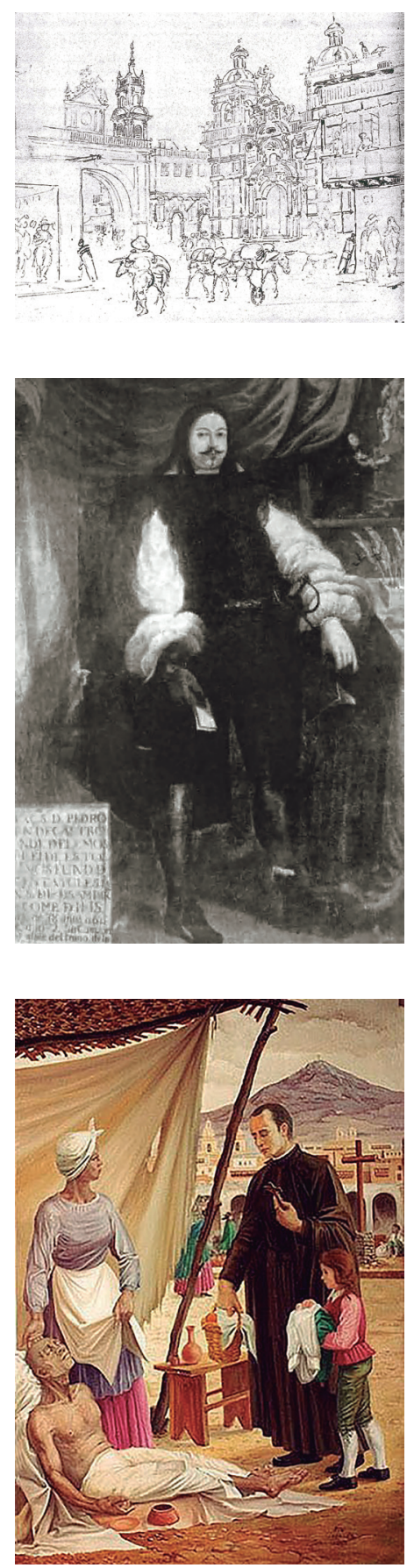

Figura 5. Dibujo inconcluso de la Plazuela de los Desamparados

Fuente: Angrand, 1972, p. 64.

Figura 6. Retrato del Conde de Lemos Fuente: Basadre, 1945, p. 4.

Figura 7. V.P. Francisco del Castillo, S. J. Óleo del artista peruano Alfredo Pittó Frías

Fuente: http://www.jrcasan.com/2008/ CARNAVAL/sermondelastreshoras.htm de una suntuosa capilla que a su costa desea fundar y fabricar de la adbolicacion de nuestra señora de los desamparados según y para el efecto que la ay y esta fundada en la dicha ciudad de valencia obra justa y pia y con que nuestra señora a obrado en quel rreyno y ciudad grandes milagros y lo probeydo sobre ellos por su Exelecia del señor conde de chinchon virrey destos rreinos y parecer dato en virtud de lo probeydo por este cabildo en tres desde mes por el doctor don sebastian de alarcon y alcoser y contador thomas de paredes rregidores y tratadosse y conferdosse largamente sobre lo suso dicho se acordó que en conformidad del dicho parecer y atendiendo a las caussas propuestas en el pedimiento de la parte y a lo que rredunda en seruicio de dios y bien desta republica y no militar ynconbiniente que lo ynpida se le puede señalar siendo su Exelencia seruido el sitio y lugar que en el cinco baras para capilla y sacristía que comiensen desde el ultimo caxon o poco después del hasta cumplir este numero a la larga por la asequia que ba de agua al molino fundado en ella los cimintos y que tenga diez baras de ancho lo qual se entiende sin perjuicio del derecho que la hermandad de la caridad pueda tener a este ministerio conforme a sus hordenancas y estatutos- (LCL)

Luego de construirse la capilla, la familia del comerciante Bartolomé Calafre continuó con el cuidado de la misma. En el año 1657, la que por entonces era la custodia de la capilla, doña Úrsula de Morales, cedió los derechos de posesión a la orden jesuita, regida entonces por el padre Francisco del Castillo.

Bajo el cuidado del padre del Castillo es que se inició la construcción de la Iglesia de Nuestra Señora de los Desamparados. El templo fue construido entre 1669 y 1671, bajo la dirección del alarife Manuel Escobar. El ambicioso proyecto contempló también la construcción de una casa y convento de un claustro para los padres jesuitas, y una escuela donde se impartirían clases para los niños desamparados de la ciudad. Benvenutto afirma al respecto que "junto a la iglesia, se alza la preciosa portadilla del callejón que conducía a las aulas de la latinidad que sostuvieron los jesuitas antes de su expulsión y en la que instruían gratuitamente a quinientos niños, desde el Chistus hasta retórica Latina y la Historia de las Indias" (1932, p. 62) (Figura 5):

Mucho influyó para la realización de esta iglesia el apoyo brindado por el virrey Conde de Lemos, quien estuvo dispuesto a financiar buena parte de la construcción, pues era fiel devoto de la Virgen de los Desamparados. Tras la construcción de la iglesia el virrey era asiduo visitante de la iglesia, e incluso llegó a solicitar en su testamento que su cuerpo reposara en un mausoleo dentro de esta, hecho que finalmente se concretó tras su fallecimiento en 1672. La urna que contenía el corazón del virrey fue colocada a los pies de la imagen de la Virgen y se mantuvo en ese lugar hasta la demolición del templo (Figuras 6 y 7 ).

Es con la construcción de la Iglesia de los Desamparados que el espacio se consolida como la Plazuela de los Desamparados. Crónicas y relatos que llegan a nuestro tiempo afirman que este fue un espacio que albergó una intensa actividad urbana, como muchos otros en la ciudad, donde la actividad religiosa era constante, además de ser también un espacio donde los niños transitaban para recibir las clases de latín que los padres jesuitas impartían en la escuela al lado del templo. Complementaban esta actividad las tiendas o cajones de comerciantes que estaban en uno de los bordes de este espacio público, así como el tránsito de mercaderes y ciudadanos que llegaban del Puente de Piedra y eran recibidos por la plazuela (Figuras 8,9 y 10).

Décadas después, el ascenso de la Casa de Borbón en España pronto trajo consecuencias en el Imperio español. Los jesuitas, acusados de conspiradores contra la Corona, fueron expulsados de España y sus colonias en el año 1767, y sus bienes fueron confiscados y dados a terceros. La iglesia de los Desamparados, como bien perteneciente a esta orden, corrió la misma suerte: fue confiscada y la administración entregada a un capellán, y el convento fue repartido a terceros. Este suceso trajo como consecuencia que la iglesia quedara cerrada para el público, y recién fuese reabierta años después. $\mathrm{A}$ 
inicios del siglo XIX, los últimos custodios de la iglesia renunciaron a ser capellanes de la misma, por lo que el templo nuevamente fue cerrado.

Durante la etapa de Independencia y la instauración de La República, la Plazuela de los Desamparados no sufrió mayores alteraciones; sin embargo, su dinámica urbana había disminuido por el cierre de la iglesia. Durante la segunda mitad del siglo XIX, se hizo evidente el inicio del declive de este espacio público. La iglesia decayó notablemente debido al abandono de las autoridades y a que el Arco del Puente de Piedra, que había sufrido los embates de los sismos y fue reparado en diversas oportunidades, desapareció definitivamente tras un incendio en 1879, días antes de que iniciara la guerra con Chile (Figuras 11, 12, 13, 14 y 15).

Trascurrida la Guerra del Pacífico, durante la etapa de 'Restauración Nacional', doña Jesús Iturbe de Piérola, esposa del entonces presidente Nicolás de Piérola, decidió realizar la remodelación de la Iglesia de los Desamparados. El cambio más notorio fue el reemplazo de la antigua fachada barroca por una nueva, de estilo neoclásico. Vargas Ugarte comenta al respecto que "En el año de 1894 se emprendió su restauración (de la Iglesia de los Desamparados), pero más que este nombre habría de darle el de desfiguración" (1963, p. 81), así como opina que "Por desdicha, la restauración adoleció de graves defectos. Lejos de conservar la fachada, originalísima y muy dentro del estilo que se ha llamado jesuita, se la transformo totalmente, adoptando un estilo de líneas sobrias que no decía bien con su fisionomía colonial" (1963, p. 78).

Esto no hace más que evidenciar que la nueva fachada de la iglesia no contribuyó mucho a realzar su importancia ni la historia que llevaba consigo. Las torres adornadas con acabados almohadillados fueron cambiadas por torres prismáticas con sobrias líneas horizontales, la forma de los campanarios que continuaban a los cuerpos las torres fueron cambiados por vanos rectangulares poco vistosos y las cúpulas que remataban las torres fueron reemplazas por balaustres. También se reemplazó el óculo que tenía la calle central de la portada por un rosetón de gran tamaño. Y, finalmente, el remate de la calle fue cambiado por un frontispicio propio del estilo neoclásico. Casi no quedó rastro de la hermosa fachada barroca diseñada por Escobar (Figuras 16 y 17).

Por aquellas épocas el atrio de la iglesia también se vio afectado por el paso de los tranvías, pues una de las rutas de dicha red pasaba por la plazuela, frente a la iglesia, en su atrio; esta quedó partida y disminuyó su dimensión.

En las primeras décadas del siglo XX, ocurrió un hecho gravitante para el destino de este espacio público: la reedificación de Palacio de Gobierno. Este proyecto, que empezó a gestarse tras el incendio que destruyó parte de la antigua Casa de Pizarro, tuvo por principales autores a los arquitectos Jean Claude Sahut y Ricardo Malachowski, en dos etapas distintas de ejecución del proyecto. Fue la última etapa de ejecución, llevada a cabo durante el segundo gobierno del presidente Oscar R. Benavides, la que comprendía la ampliación de la manzana de Pizarro en su parte posterior. Esto significó que el espacio público de la Plazuela de los Desamparados se trasforme nuevamente. Los trabajos en la parte posterior de la Casa de Pizarro iniciaron en el año 1937 con la demolición de la iglesia de Nuestra Señora de los Desamparados. La sagrada imagen tutelar y otras reliquias que en el templo se conservaban fueron trasladas a una nueva iglesia del mismo nombre, ubicada en la actual Av. Venezuela, donde hasta ahora se conservan. En este contexto se manifestaron dos posiciones en relación al tema de la modernización de la Casa de Gobierno y la destrucción de la iglesia: una a favor, la de Martín Eduardo; y otra en contra, la de Vargas Ugarte.

Martín Eduardo, en el libro De la Casa de Pizarro a Palacio de Gobierno, comenta que "Más justamente por que crece y se dilata y se engalana, y se embellece la ciudad, desmonta del marco, y así enriquecido, la a medias ya reconstruida, a medias aun olvi-
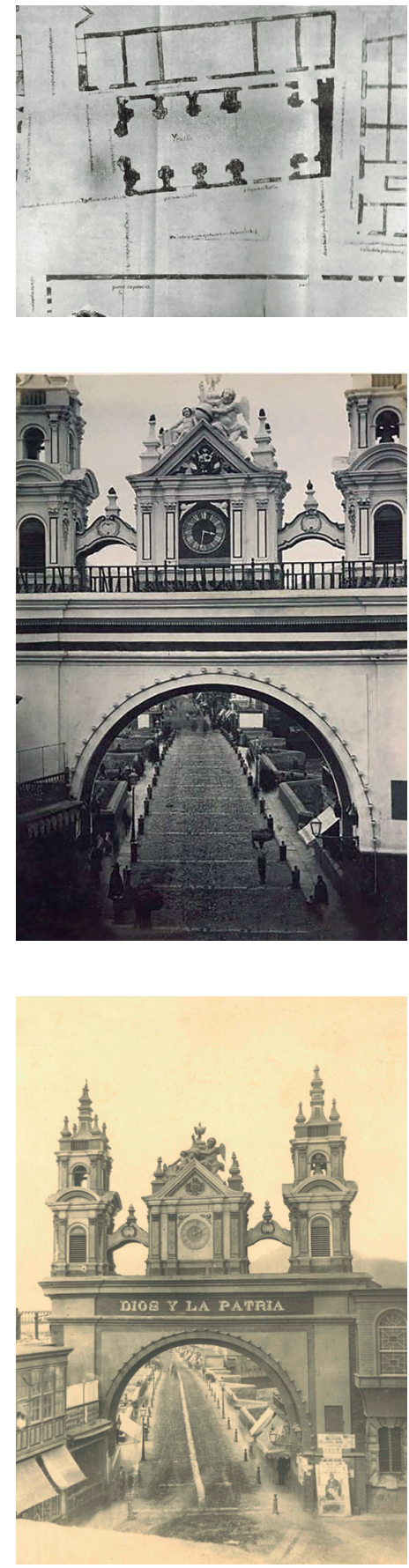

Figura 8. Plano del templo Nuestra Señora de los Desamparados Fuente: Basadre, 1945, p. 383.

Figura 9. Arco del Puente de Piedra, 1864

Fuente: https://www.pinterest.com/ pin/105975397452123997/, 2016.

Figura 10. Arco del Puente de Piedra, 1865

Fuente: Archivo fotográfico de la Municipalidad Metropolitana de Lima, 2016. 


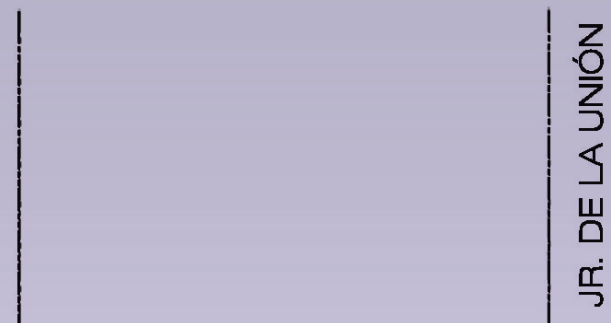

Figura 11. Elevación de los bordes de la Plazuela de los Desamparados, 1865

Fuente: Elaboración propia, 2015. dada Casa del conquistador, y hace urgente concluir las obras apenas comenzadas..." (1938, p. 297).

En opinión contraria, Vargas Ugarte afirma lo siguiente:

Nada de esto ni el haber sido cuna de la devoción de la Tres Horas el Viernes Santo, ha sido parte para impedir su demolición en época reciente, sin que razones de urbanismo o de tráfico lo exigieran, sacrificado tan hermoso y venerable monumento al inconsulto propósito de darle un mediocre jardín al Palacio de Gobierno. (1942, p. 157)

En ese contexto era evidente la polémica en torno a la desaparición de la iglesia, por lo que muchos limeños se manifestaron en contra de tal medida. Al respecto, Mattos Cárdenas comenta que "....el presidente Benavides decide demoler todo el espacio. Aún si poco antes la prensa local aseguró que con el nuevo Palacio de Gobierno se salvaría la histórica iglesia" (2016, p. 1). Como afirma el autor, la iglesia fue finalmente demolida, y así la plazuela que acompañaba a la iglesia, junto con los demás predios que conformaban este espacio público, se convirtió en el nuevo Malecón de los Desamparados (Figuras 18 y 19 ).

El malecón era ahora el nuevo nexo que permitía a los transeúntes desplazarse hacia la Estación de los Desamparados, construida en el año 1870, que por aquella época lucía 


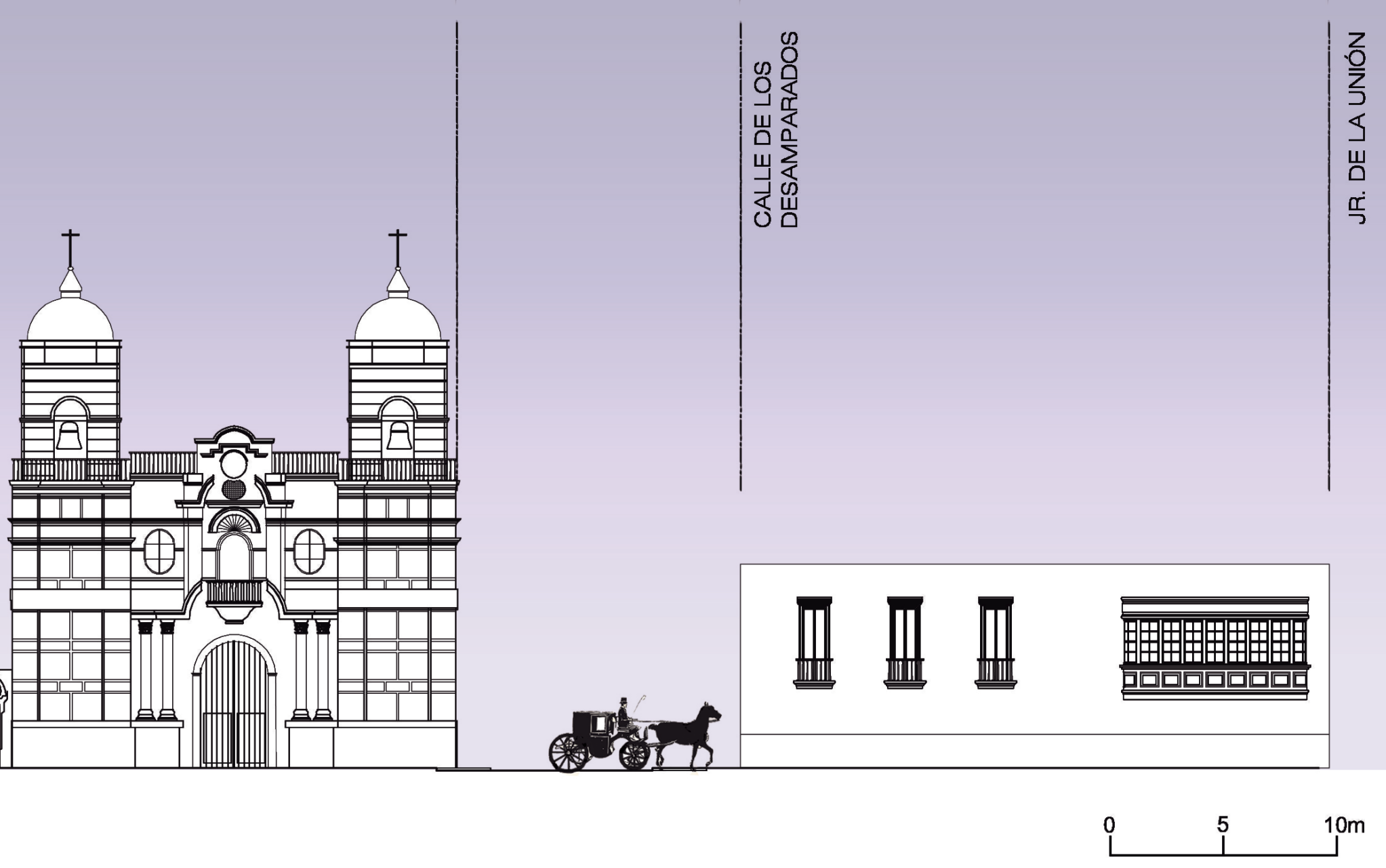

una nueva infraestructura diseñada por el arquitecto Rafael Marquina, inaugurada en 1912. El Malecón de los Desamparados permitía mirar nuevamente el río Rímac, como ya lo hacían los espacios públicos que se encontraban frente al damero de Pizarro, la Alameda de los Tajamares y la Alameda de Acho.

El crecimiento de la ciudad, en las décadas posteriores, trajo consigo el desarrollo de nuevas arterias viales que conectaban el centro de la ciudad con la periferia, incremento motivado por el aumento del uso de vehículos de transporte. El malecón pronto se convirtió en una vía para el tránsito vehicular; automóviles y buses que llegaban al centro de Lima utilizaban este espacio. Los bordes que lo configuraban eran la fachada lateral de la Estación y la fachada posterior de Palacio de Gobierno; estas edificaciones motivaron que los bordes de la calzada sean empleados como estacionamiento, uso que se fue masificando a los largo de las décadas, conforme se consolidaba el predominio del vehículo por sobre el peatón (Figura 20).

\section{Inseguridad ciudadana y dictadura urbana en el contexto del Malecón de los Desamparados}

La década de los 80 significó para nuestra historia reciente una etapa insegura y violenta, producto de la guerra interna que en nuestro país se venía desarrollando. Es 
devenir Vol. 3, Nº, JULIO-DICIEMBRE 2016, PP. $79-97$ - EstUdIOS I ISSN 2312-7570

UNIVERSIDAD NACIONAL DE INGENIERÍA, LIMA

Figura 12. Elevación del Arco de Puente de Piedra, 1875

Fuente: Elaboración propia, 2015.

Figura 13. Elevación de las fachadas de la Iglesia Nuestra Señora de los Desamparados

Fuente: Elaboración propia, 2015.

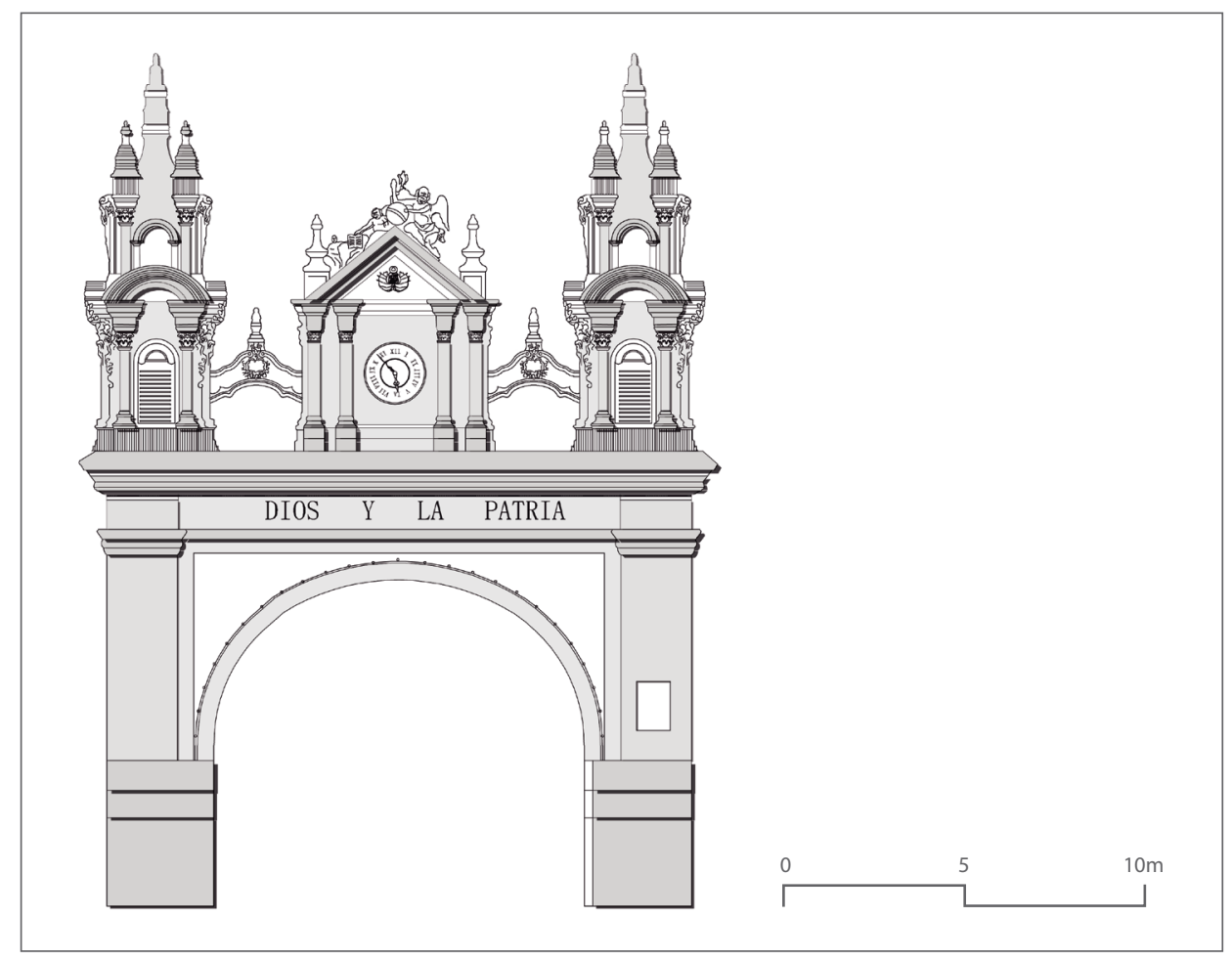

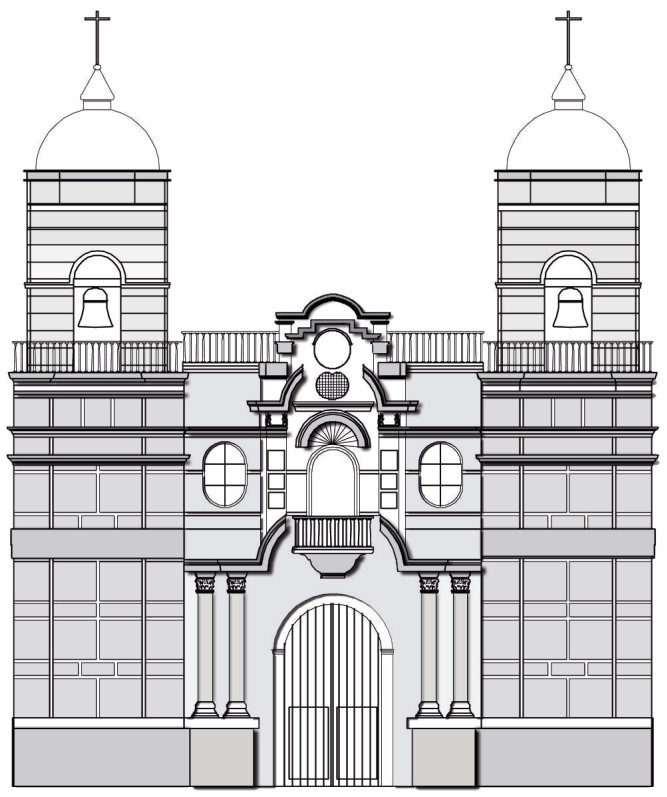

Estilo BarRoco

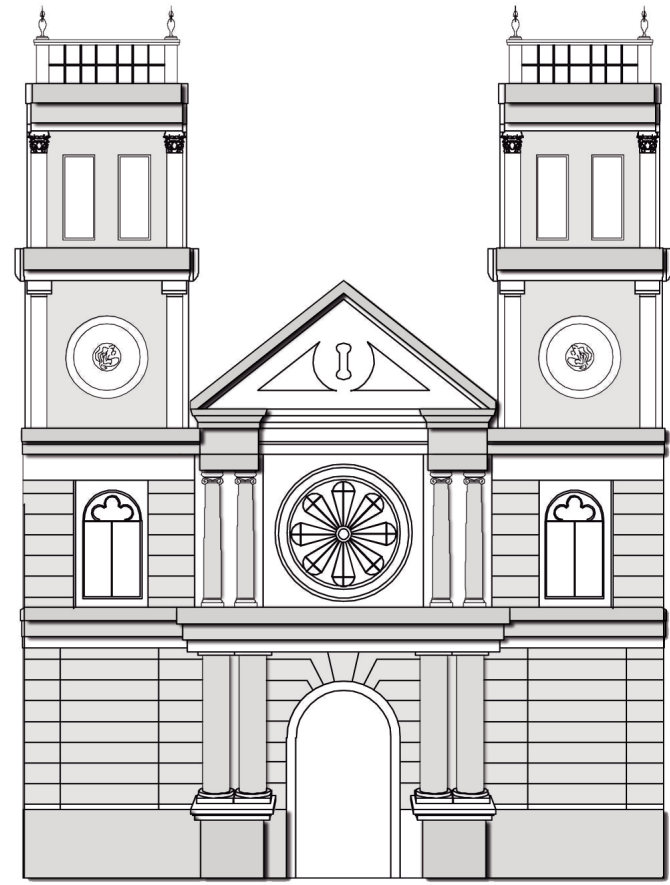

Estilo Neoclásico

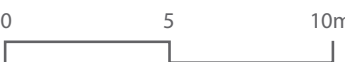



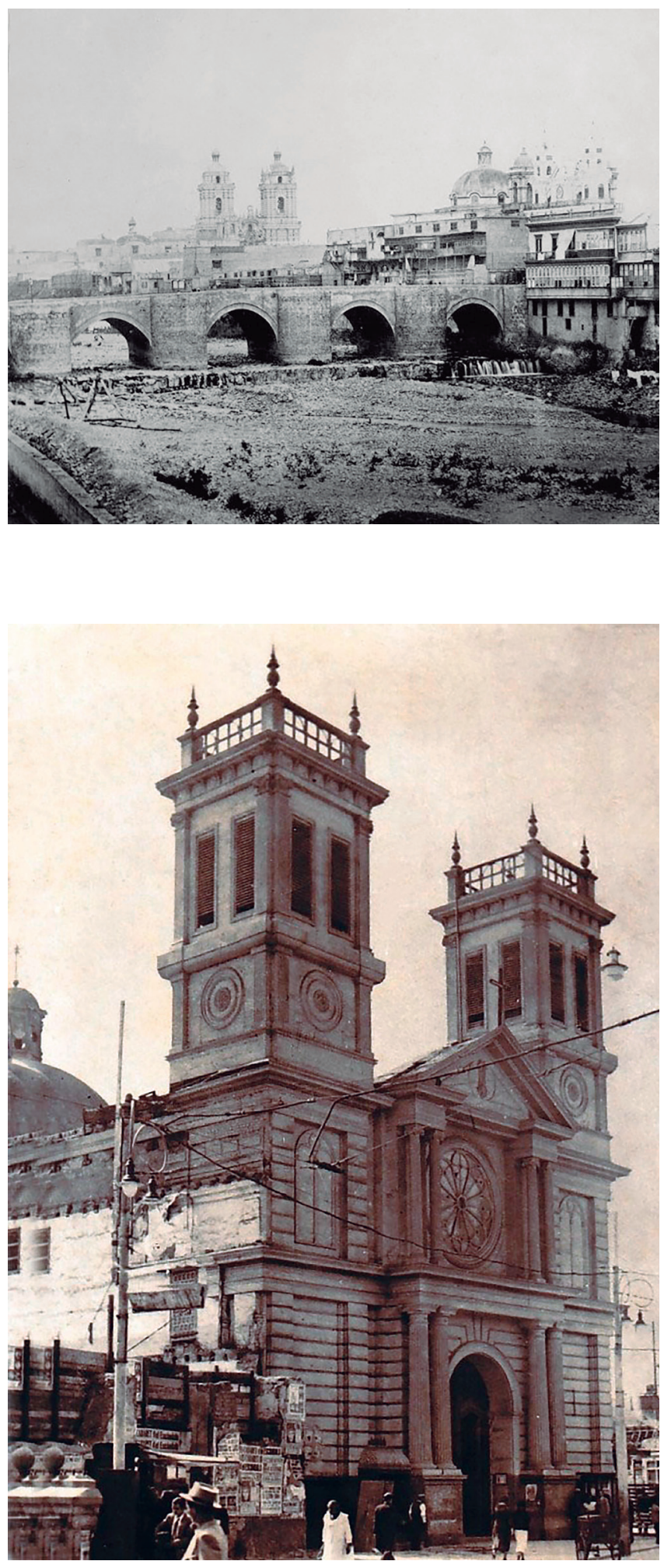
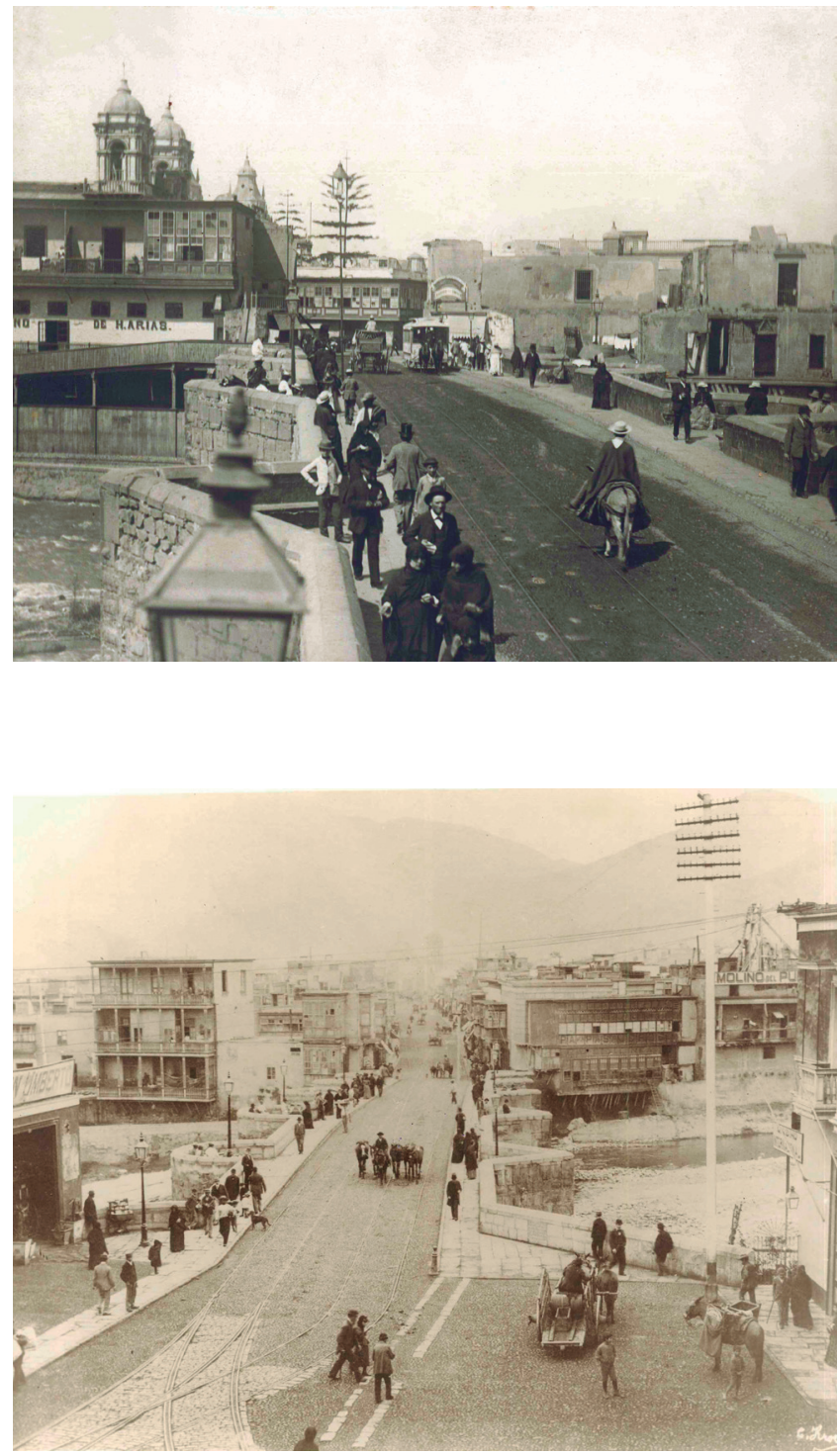

Figura 14. Vista del Puente de Piedra y del arco a mediados del siglo XIX

Fuente: http://magistoria.blogspot.pe/2014/?m=0, 2016.

Figura 15. Vista del Puente de Piedra finales del siglo XIX, tras la desaparición del arco

Fuente: Archivo fotográfico de la Municipalidad Metropolitana de Lima, 2016.

Figura 16. Iglesia de los Desamparados a inicios del siglo XX Fuente: http://antiguadesamparados.blogspot.pe/, 2016.

Figura 17. Vista del Puente de Piedra a inicios del siglo XX

Fuente: Archivo fotográfico de la Municipalidad Metropolitana de Lima, 2016. 

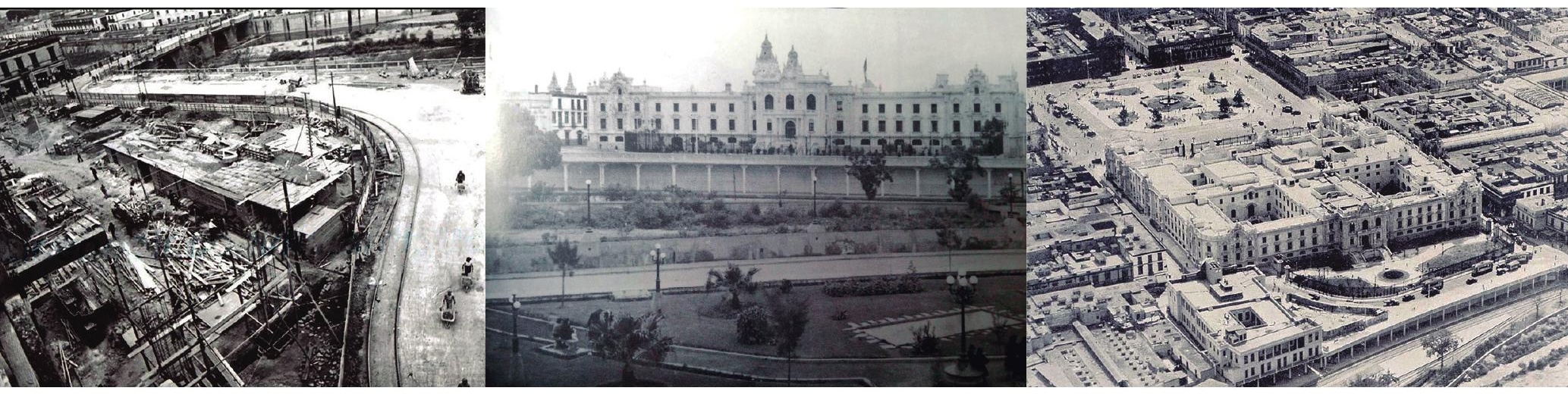

Figura 18. Construcción de los jardines de Palacio

Fuente: https://www.facebook. com/ limantigua/ photos/ a.370030289694999. 86706 . $124321064265924 / 12054138825947 /$ ?type=3\&theater, 2016.

Figura 19. Vista del Malecón de los Desamparados

Fuente: Heinz Arheidt \& Wieser, 1997, p. 27.

Figura 20. Vista de pájaro del Malecón de los Desamparados, 1942

Fuente: http://vistasdelos40s.blogspot.pe/, 2016 durante la segunda mitad de esta década cuando las acciones terroristas de Sendero Luminoso empezaron a manifestarse en la ciudad capital; uno de los principales focos de atentados fue el centro de Lima, pues en este sector de la ciudad se concentraban los poderes del Estado. La casa de gobierno y su entorno fueron objeto de varios ataques, como lo informaban los medios de la época.

Se han podido datar algunos atentados terroristas al Palacio de Gobierno, que son reflejo de lo vulnerable que era este espacio durante esa época. La Comisión de la Verdad y la Reconciliación expone sobre la situación en esa parte del Centro Histórico de Lima:

Aquí (centro de Lima) concentraron el PCP-SL y el MRTA sus acciones de sabotaje y atentados contra entidades públicas y privadas en su objetivo de sabotear el funcionamiento estatal. En efecto, en 1991 entre el 60 y 70\% de los atentados en Lima Metropolitana se sucedieron en estos distritos, convertidos en el blanco central de la estrategia de «caja de resonancia». (2003, p. 411)

El Centro de Estudios y Promoción del Desarrollo (DESCO), en su publicación Violencia política en el Perú, identifica la secuencia de atentados ocurridos en las cercanías de Palacio de Gobierno, que tuvieron lugar principalmente durante la segunda mitad de la década de los 80:

- 7 de junio de 1985: Coche-bomba en la Plaza Mayor a pocos metros de Palacio de gobierno

-14 de julio de 1986: Se desactiva dos cargas explosivas cerca a Palacio de Gobierno

El diario El Comercio en una nota periodística informa al respecto: "Tres artefactos explosivos fueron colocados en el campo ferial Polvos Azules, pero la policía logro desactivarlos al mediodía del domingo, evitando estallar" (1986, p. A11).

- 5 de agosto de 1987: Ataque a Palacio de gobierno con lanzacohetes

La publicación de DESCO, detalla al respecto lo siguiente:

Subversivos atacaron Palacio con granadas-cohete tipo Instalassa, disparadas desde el techo de un antiguo inmueble del Rímac, o desde un vehículo en movimiento que circulaba por la Vía de Evitamiento. Dos granadas, disparadas con fusiles automáticos, impactaron en una de las ventanas de la parte posterior de la Casa de Pizarro, donde está la residencia presidencial. Uno de los proyectiles abrió un boquete en la pared de concreto y otro penetró en el Salón de Edecanes de Palacio. La autoría de las explosiones en Palacio de Gobierno fue reivindicada por el MRTA. (1989, p. 215) 
Estos atentados terroristas motivaron que el antiguo Malecón de los Desamparados fuera cercado en ambos extremos a finales de la década de los 80 para impedir el libre tránsito de vehículos y peatones. Este suceso contribuyó a afianzar el uso privado de esta calle como estacionamiento particular. Tanquetas militares y bloquetas de concreto ahora se sumaban al paisaje urbano de este espacio público, en íntima relación con la paupérrima situación en la que el Centro Histórico se había sumido por aquella época, producto de la apropiación de espacios públicos por parte del comercio ambulatorio, el intenso tránsito vehicular, entre otros. Con la cancelación del servicio de pasajeros de la estación de los Desamparados y la inactividad de este edificio en la década de los 90, este espacio pasó a ser de uso exclusivo de Palacio de Gobierno. La privatización de este espacio público y el cambio de uso por parte de la autoridad consolidaron la pérdida del malecón para el resto de la ciudad (Figura 21).

\section{¿Por qué recuperar el Malecón de los Desamparados?}

Lo expuesto en las anteriores líneas pone de manifiesto la relevancia histórica de este espacio público en la historia de la ciudad de Lima. El espacio donde alguna vez estuvo la Plazuela de los Desamparados y posteriormente el malecón del mismo nombre posee además del valor histórico otros valores que permiten reflexionar sobre su importancia:

- Valor simbólico: La zona que conformaron la Plazuela de los Desamparados, la iglesia, el Puente de Piedra y el Arco fue un importante nicho de la actividad urbana en Lima durante los 300 años de su existencia. La riqueza de la dinámica urbana que tuvo, sumada a la importancia de los hitos que conformaban el espacio, configura su riqueza histórica y la memoria del lugar. La memoria del lugar, que sería puesta en valor junto con la renovación de la zona, contribuiría a generar una identificación con la población, que así podría tener conocimiento de su pasado y la relevancia del mismo.

- Valor formal: A pesar de que el espacio de la Plazuela de los Desamparados ya ha desaparecido, y con ello la arquitectura que la conformaba, es importante resaltar la arquitectura que acompañaba el espacio en la actualidad. La arquitectura monumental conformada por la Casa de Gobierno, la Casa de la Literatura, el Puente de Piedra y la Casa Aliaga contribuyen a sumar en el valor formal que de por sí ya tenía. La renovación y la puesta en valor del Malecón de los Desamparados contribuirían a resaltar notoriamente la arquitectura que conforma sus bordes. La apertura para

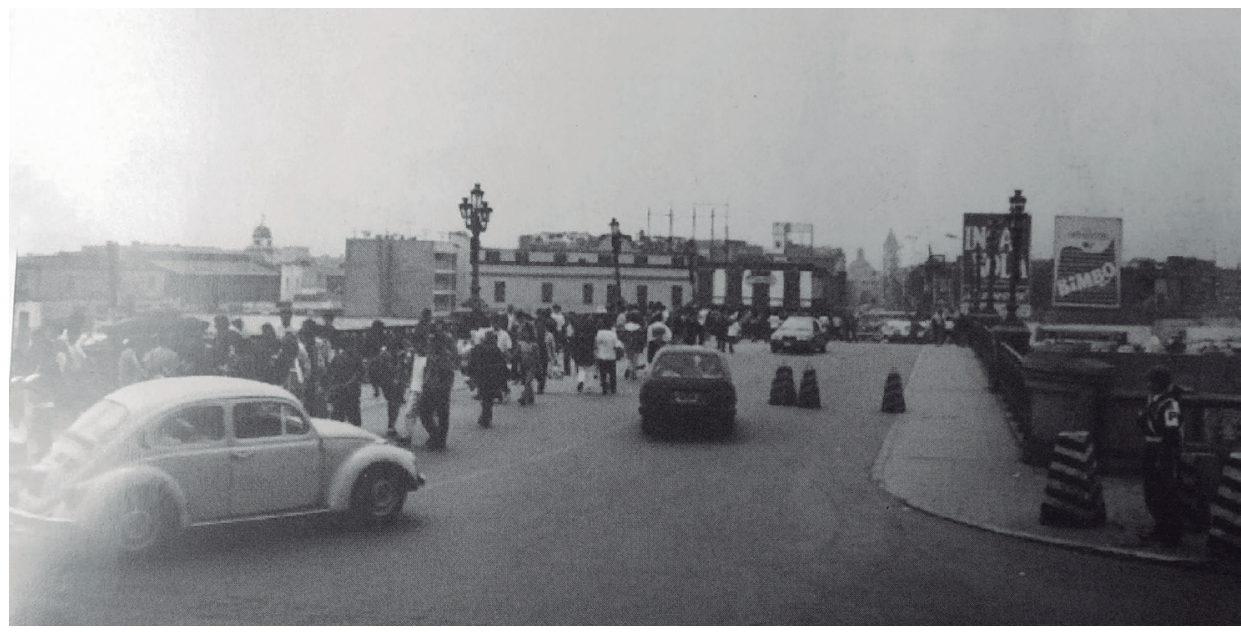

Figura 21. Vista del Puente de Piedra; se aprecia el cerco militar a la primera cuadra del Jr. Áncash Fuente: Heinz Arheidt \& Wieser, 1997, p. 21 . 
Figura 22. Vista actual de la primera cuadra del Jr. Áncash desde Jr. Carabaya

Fuente: Archivo fotográfico Ravines, 2015.

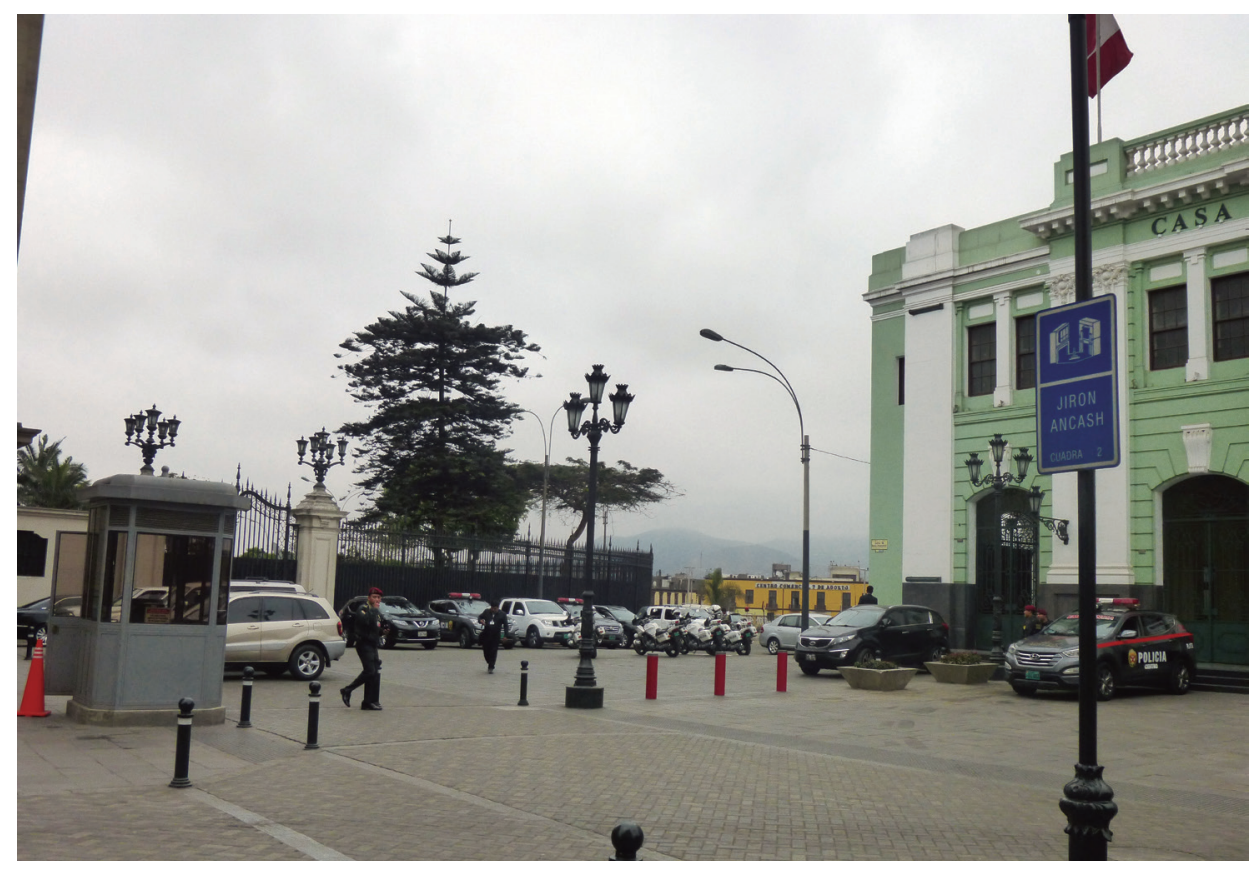

el público permitiría la apreciación de la arquitectura desde otro punto de referencia, además de ser un nuevo espacio de recibo y desfogue para las edificaciones.

- Valor de uso: Actualmente disgregado del tejido urbano, su recuperación para la ciudad permitiría que esta recobre la permeabilidad que actualmente es impendida por el cerco en sus bordes. La reapertura de este espacio público permitiría volver a conectar la calle Polvos Azules, donde actualmente se encuentra ubicada la Alameda con el Jr. Áncash, que conduce al Templo de San Francisco y al actual Parque de la Muralla.

En el entorno inmediato, es posible notar que la mayoría los inmuebles y espacios públicos que rodean al antiguo malecón han sido puestos en valor. Para ejemplificar esto podemos citar algunas acciones:

- El reordenamiento del comercio ambulatorio en el Jr. De la Unión, llevado a cabo durante el mandato del alcalde Alberto Andrade, quien planteo una política de recuperación del Centro Histórico de Lima.

- La construcción de la Alameda Chabuca Granda, proyecto que permitió la renovación de la calle Polvos Azules, liberada tras años de estar ocupada por los ambulantes del campo ferial del mismo nombre.

- La transformación de la Estación de los Desamparados en la Casa de la Literatura, el año 2008. La apertura de este centro cultural educativo para la comunidad dotó de un nuevo uso al inmueble y permitió su puesta en valor.

El espacio que conformó la plazuela de los Desamparados volvería a tener la función de espacio articulador del tejido urbano, al unir Chabuca Granda con el Jr. Áncash, lo cual formaría así un nuevo eje urbano, transversal al eje del Jr. De la Unión. Esto motivaría el uso por parte de la población, que sería principalmente peatonal. Tal hecho que favorecería a los monumentos que en sus bordes se ubican, pues al igual que el Jr. Ucayali, la apreciación de estos seria mayor (Figuras 22 y 23). 


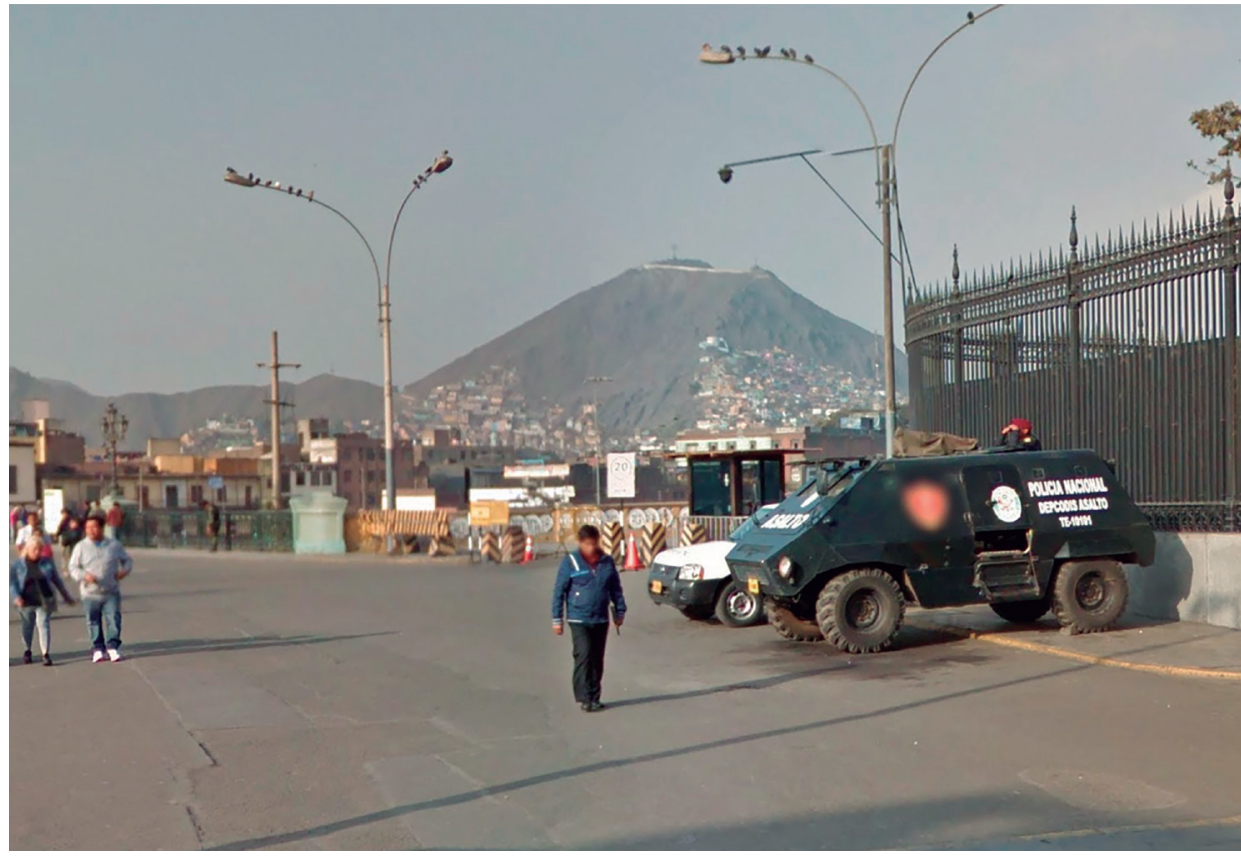

\section{El Malecón de los Desamparados y la renovación de espacio públicos en zonas monumentales}

El sector urbano donde se encuentra inmersa hoy la primera cuadra del Jr. Áncash, otrora Malecón de los Desamparados, es una área del centro histórico que cuenta con mucha riqueza patrimonial: allí se encuentran edificios como el Palacio de Gobierno, la Casa de los Desamparados y la casa Aliaga, así como los espacio públicos del Puente de Piedra y la alameda Chabuca Granda, los cuales configuran un espacio urbano de importancia. El Malecón de los Desamparados, en tanto espacio público, debería ser parte de esta configuración urbana patrimonial. Volver a darle valor como tal sería uno de los objetivos importantes de esta renovación. Hacer de este un espacio que pueda ser usado por todos es esencial, pues permitiría generar un nuevo acceso a las edificaciones adyacentes de carácter monumental.

En este contexto, es importante mencionar la categorización patrimonial para inmuebles y espacios públicos propuesta por el Plan Maestro del Centro Histórico de Lima al 2035, en el cual se define dentro de tal categorización del patrimonio al Malecón de los Desamparados, hoy conocido como la primera cuadra del Jr. Áncash: está considerado como 'Entorno', es decir, un espacio que forma parte del contexto físico inmediato de los inmuebles o monumentos de carácter patrimonial.

Asimismo, en la clasificación del Plan Maestro se señala la categoría 'Ambiente Urbano Monumental'. Esta abarca espacios públicos que presentan un "valor urbanístico en conjunto" (MML, , 2014, p. 32). La Plaza Mayor, la Plaza San Martín, e inclusive parte de calles como el Jr. De la Unión o el mismo Jr. Áncash se consideran dentro de esta categoría. Los argumentos que permiten sustentar la incorporación del Malecón de los Desamparados (cuadra uno del Jr. Áncash) a la categoría de 'Ambiente Urbano Monumental' son diversos desde la perspectiva urbana y patrimonial. Además, este espacio público posee las principales características definidas por la categorización del Plan Maestro del Centro Histórico de Lima al 2035; y posee otros valores anteriormente mencionados que lo harían merecedor de ser considerado bajo tal denominación.
Figura 23. Vista actual de la primera cuadra del Jr. Áncash desde Jr. De la Unión

Fuente: Google Earth, 2016. 
El Plan Metropolitano de Desarrollo Urbano de Lima y Callao (PLAM 2035) contempla dentro del "Programa Urbanístico de Patrimonio y Paisaje" abordar la regeneración de patrimonio edificado y sus entornos: "[El programa Urbanístico de Patrimonio y Paisaje] Plantea una mirada propositiva sobre sus bienes patrimoniales, incluyendo el paisaje natural y urbano como tal, para generar valor en sus entornos a través de la creación de proyectos que repercutan directamente en su conservación" (MML, 2014, p. 551).

Uno de los objetivos del programa es la incorporación de espacios públicos que contribuyan a la mejora del paisaje patrimonial existente, es decir, espacios que conecten el tejido urbano con el patrimonio existente. Con este propósito se plantea la reutilización de "espacios y vacíos urbanos sin uso, relacionados al patrimonio, otorgándoles un nuevo rol en la disminución de brechas de déficits de equipamientos, áreas de recreación, culturales, etc." (MML, 2014, p. 551).

En esta propuesta se promueven las políticas de recuperación y renovación urbana en diversos espacios, fácilmente aplicables para la realidad de la cuadra uno del Jr. Áncash (Malecón de los Desamparados), pues es parte del entorno de edificios patrimoniales y está en la ribera del río Rímac ('Entorno Paisajístico Natural').

Una de las propuesta de articulación del Damero de Pizarro con el distrito del Rímac planteadas por el PLAM 2035 es el "rediseño vial y mejoramiento del cruce del río, renovación y valoración del espacio urbano del Jr. Carabaya-Chiclayo-Alameda de los Descalzos" (MML, 2014, p. 508) Como parte de esta propuesta se plantea abordar el tratamiento de renovación urbana del Malecón de los Desamparados. Esto constituye una gran oportunidad para la revaloración de este espacio público, hoy privatizado, de forma que se convierta en un nodo importante que articule el tejido urbano y permita permeabilidad urbana entre la calle Polvos Azules (alameda Chabuca Granda) y la segunda cuadra del Jr. Áncash.

Por otro lado, el PLAM 2035 presenta un capítulo destinado a "Proyectos Estructurantes del Sistema de Espacios Abiertos e Infraestructura Ecológica", el cual dentro de la cartera de proyectos estructurales cuenta con uno destinado a recuperación del río Rímac para la ciudad, denominado "Plan Director del Río Rímac". Este plan introduce una nueva visión del río Rímac como eje urbano estratégico para la ciudad, retoma la concepción de espacio natural y lo asocia como un corredor cultural. La estrategia del corredor cultural permite conectar el río Rímac con las áreas patrimoniales que se encuentran en la zona del centro histórico de la ciudad. Este nuevo enfoque permite la creación de espacios en la interfaz del río y las áreas patrimoniales, para permitir la protección y renovación de los monumentos y espacios con valor patrimonial para la ciudad. La creación de parques culturales y el tratamiento de bordes en las distintas partes de la ribera del río Rímac podrían constituir el principal vínculo entre el río y el antiguo casco urbano de Lima.

En este sentido, se puede considerar que la primera cuadra del Jr. Áncash constituye una interfaz entre el antiguo casco del centro histórico de Lima y la ribera del río Rímac. Es por ello que la recuperación del antiguo Malecón de los Desamparados, ocupado actualmente por vehículos particulares, podría sentar el primer precedente para la habilitación y creación de espacios públicos en los bordes del río Rímac, es decir, la recuperación de ambas riberas del 'río hablador', tanto la parte de la antigua Plazuela de los Desamparados como aquella ribera donde se ubicaba la alameda de Acho. Ello permitiría volver nuevamente la mirada hacia el paisaje natural ribereño del río. La recuperación de este espacio público permitiría la recuperación del tejido urbano en ese sector del Centro de Lima, lo cual convertiría ese lugar en un nuevo punto de visualización de la ribera del río Rímac. A la vez, su estratégica ubicación convierte a la primera cuadra del Jr. Áncash en un espacio articulador, no solo entre los espacios y edificaciones que constituyen sus bordes, sino también entre el río y la ciudad. 
La recuperación de este espacio público, permite también reflexionar un poco más sobre los elementos que constituyeron la génesis de la Plazuela de los Desamparados. Uno de los importantes hitos urbanos que formaba parte de los bordes de la Plazuela era el Arco del Puente de Piedra, destruido a finales de siglo XIX. Cabe resaltar que estuvo en la mente del arquitecto Harth-Terré hacer una remembranza del desaparecido arco, hecho que se plasmó en su propuesta de remodelación de la Plaza de Armas presentada en los años 40. La propuesta incluía construir unos arcos a modo de cierre en los pasajes Santa Rosa y Olaya; sin embargo, dicho planteamiento no se llegó a concretar.

El hecho de recuperar el carácter simbólico que tuvo este hito urbano dentro de la configuración de la Plazuela de los Desamparados, y a la vez de generar la relación de pertenencia de la población con su pasado y sus monumentos desaparecidos, podrían ser algunas de las causas que motiven pensar sobre la reconstrucción y revaloración del patrimonio desaparecido.

Desde la concepción cíclica del tiempo característica de las culturas orientales, se plantea una visión que va más allá de la materialidad de un monumento. Valores como el simbólico, el de uso, el didáctico y la preservación del patrimonio inmaterial (técnicas constructivas, tradiciones, entre otros) son las premisas que respaldan la reconstrucción de ciertas piezas de la ciudad, como es el caso del Arco del Puente de Piedra.

Los ejemplos sobre las reconstrucciones en ciertas circunstancias son diversos. Existen experiencias como la reconstrucción de la Torre de Venecia y el puente de Mostar, que al nivel de hitos urbanos muestran la importancia de la recuperación de ciertos elementos que configuran el tejido urbano. También cabe tomar en cuenta casos a nivel urbano, como el de la ciudad de Dresde en Alemania tras la Segunda Guerra Mundial, muestra de este tipo de intervención. De ese caso particular cabe resaltar la reconstrucción de Frauenkirche, iglesia luterana del siglo XVIII, proceso en el cual el exhaustivo trabajo de investigación fue una pieza clave para llevar a cabo una reconstrucción fiel a la edificación original.

Asimismo, el lamentable suceso del terremoto ocurrido en Italia en agosto de 2016 pone nuevamente sobre la palestra el tema de las reconstrucciones arquitectónicas, en específico en torno al caso de la antigua ciudad de Amatrice. Las autoridades y la comunidad de esta localidad italiana, rica en historia y monumentos arquitectónicos que datan de la época romana, han pensado como acción inmediata tras el desastre su pronta reconstrucción. El primer ministro italiano Metteo Renzi ha solicitado que el reconocido arquitecto Renzo Piano lidere el grupo de profesionales encargados de esta compleja tarea.

En esa línea, la arquitecta española Gómez Robles (2010) comenta en relación a la reconstrucción del patrimonio desaparecido que "Evidentemente ante la gran pérdida material y emocional que supone la destrucción repentina de una ciudad, la decisión de reconstruir parcial o globalmente la misma, sean cuales sean los métodos, es legítima y en ocasiones necesaria para devolver a la población su identidad" (p. 6).

Desde este punto el Arco del Puente de Piedra podría ser un elemento a reconstruir, pues, como hito urbano, este podría concentrar en un solo elemento lo que en su tiempo constituyó ese espacio público de la Plazuela de los Desamparados, así como expresar una época de la historia local con toda la carga simbólica y de memoria que eso significa. Ello, a la vez, permitirá recobrar el valor de uso y el carácter de esta zona del Centro de Lima, materializado en el arco, que funciona como 'puerta de entrada' al Centro Histórico desde el norte de la ciudad. Se podría poner también en discusión la recuperación del mismo Puente de Piedra, ícono de nuestra ciudad que se encuentra muy deteriorado por las mutilaciones y modificaciones que ha sufrido, acciones condenables que devalúan nuestro patrimonio arquitectónico. En suma, junto con el 
malecón de los Desamparados y el Puente de Piedra, el Arco del viejo puente es un fragmento de la ciudad que valdría la pena recuperar de manera integral.

Es válido reflexionar sobre la importancia de un espacio público como el de la primera cuadra del Jr. Áncash (otrora de la Plazuela de los Desamparados) para la ciudad. La carga histórica y simbólica de este espacio del Centro de Lima es importante, pues constituye una pieza clave para justificar su recuperación y puesta en valor. Las cualidades urbanas como la permeabilidad y su valor de uso, entre otras, además de su estratégica ubicación, son razones que suman para considerar un proyecto de renovación urbana integral. La renovación urbana de este espacio podría realizarse mediante diversas acciones concretas, como la reapertura del espacio público de la primera cuadra del Jr. Áncash, la propuesta de un diseño acorde con la envergadura y el contexto del lugar, y la recuperación morfológica del antiguo Puente de Piedra y el arco triunfal de ingreso. Esta recuperación contribuiría notablemente a la revaloración del patrimonio existente en la zona y de la ciudad; a la vez, permitiría dar a conocer la memoria del lugar y recobrar los valores que en épocas anteriores dotaron a este espacio de Lima de un carácter especial, poco común en otras partes del centro histórico.

\section{Referencias}

Agustín Borneo, R. (2011). Las murallas de Lima y el Callao. Lima, Perú: Universitaria.

Angrand, L. (1972). Imagen del Perú en el siglo XIX. Lima, Perú: Carlos Milla Batres.

Archivo fotográfico de la Municipalidad Metropolitana de Lima.

Basadre, J. (1945). El Conde de Lemos y su tiempo (Bosquejo de una evocación y una interpretacion del Peru a fines del siglo XVII). Lima: Empresa Gráfica Scheuch.

Benvenutto M., P. (1932). Quince plazuelas, una alameda y un callejón. Lima en los años de 1884 a 1887. Lima, Perú:Teodoro Schevch.

Concejo Provincial de Lima (1963). Libro de Cabildo de Lima. 1557-1568. Lima, Perú: Imp. Torres Aguirre.

Concejo Provincial de Lima (1963). Libro de Cabildo de Lima. 1628-1630. Lima, Perú: Imp. Torres Aguirre.

Terroristas dinamitan 5 bancos y colocan bombas en "Polvos Azules". (15 de julio de 1986). El Comercio, p. A11.

Comisión de la Verdad y Reconciliación. (2003). Comisión de la verdad y la reconciliación, informe final. Lima, Perú: Autor.

Centro de Estudios y Promoción del Desarrollo (1989). Violencia política en el Perú 1980-1988 (Vol. I). Lima, Perú: Autor.

Gómez Robles, L. (2 de setiembre de 2010). Todo patrimonio. Recuperado de http://www. todopatrimonio.com/actas-de-congresos/222-actas-del-x-congreso-internacional-cicop-2010-rehabilitacion-del-patrimonio-arquitectonico-y-edificacion-perspectivas-contemporaneas-y-nuevas-dimensiones-del-patrimonio

Gunther, J. (1983). Planos de Lima 1613-1983. Lima, Perú: Petroperú.

Gunther, J. \& Lohmann, G. (1992). Lima. Lima, Perú: MAPFRE.

Google earth. (s.f.). Recuperado en 2016 de https://www.google.com/intl/es/earth/

Heinz Arheidt, K., \& Wieser, M. (1997). Lima, ayer y hoy. Lima: BPR.

Martín-Pastor, E. (1938). De la vieja casa de Pizarro al nuevo palacio de gobierno. Lima, Perú: Ministerio de Fomento y Obras Públicas del Perú.

Mattos-Cárdenas, L. (10 de mayo de 2016). Espacio de los Desamparados antes del puente [texto sin publicar]. Roma, Italia.

Municipalidad Metropolitana de Lima. (12 de mayo de 2015). Plan Metropolitano de Desarrollo Urbano de Lima. Recuperado en 2015 de http://limatieneunplam.blogspot.pe 
Municipalidad Metropolitana de Lima. (12 de mayo de 2015). Plan Maestro del Centro Histórico de Lima al 2025. Recuperado en 2015 de http://limatieneunplam.blogspot.pe

Pinterest. (s.f.). Recuperado en 2016 de https://www.pinterest.com

Pinto Rojas, A. (2 de diciembre de 2014). Magistrora. Recuperado el 2016, de http://magistoria. blogspot.pe

Rodríguez Castillo, D. (11 de abril de 2012). Antigua Iglesia de Desamparados en Lima-Perú. Recuperado el 2015, de http://antiguadesamparados.blogspot.pe/

Rodriguez Castillo, D. (25 de noviembre de 2013). Antiguas Vistas Aéreas de los años 40s. de Lima - Perú. Recuperado el 2015, de http://vistasdelos40s.blogspot.pe/

Saenz Mori, I. D. (2004). Ciudad y fortificación: las murallas ribereñas de la ciudad de Lima (16871872). Lima, Perú: Municipalidad Metropolitana de Lima.

Saénz Mori, I. D. (2015). El damero en dicusión. Terra Brasilis, 17, 1-22.

Vargas Ugarte, R. (1942). De la conquista a la República, artículos históricos. Lima: Librería e Imprenta Gil.

Vargas Ugarte, R. (1963). Los jesuitas del Perú y el arte. Lima, Perú: Talleres Iberia.

Velaochaga, G. L. (febrero de 2008). El carnaval y el sermón de las tres horas. Recuperado en 2015 de http://www.jrcasan.com/2008/CARNAVAL/sermondelastreshoras.htm

Velasquez Gonzalez, V. (1 de junio de 2010). Lima antigua. Recuperado en 2016 de https://www.facebook.com/limantigua/photos/ a.370030289694999.86706.12432106426 $5924 / 412054138825947 /$ ?type=3\&theater 